\title{
O LIVRO DIDÁTICO PÚBLICO DE INGLÊS: UMA ANÁLISE DA ABORDAGEM INTERCULTURAL DAS PROPOSTAS DE LEITURA
}

\author{
Marcele DAGIOS, Mestrado em Educação UFPR, CELIN-UFPR \\ Caroline TORTATO, Mestrado em Educação UFPR, CELIN- UFPR
}

\begin{abstract}
Resumo: O livro didático público de língua estrangeira do Estado do Paraná em uso desde 2009, procura abordar de maneira diferenciada o ensino de língua inglesa através do uso de textos, tentando seguir uma proposta de trabalho baseada na perspectiva sociológica bakhtiniana de linguagem. Por meio deste trabalho, tenta-se demonstrar a relação entre a teoria da linguagem defendida pelo Círculo de Bakhtin e os textos presentes no livro, relacionando os aspectos interculturais e o ensino de inglês. A partir da escolha de uma unidade temática, a pesquisa analisa os textos e as atividades propostas a fim de verificar se a intenção dos autores de ensinar a língua inglesa através da perspectiva sociológica de linguagem é efetivada, demonstrando os pressupostos da teoria do Círculo e as relações presentes nas Diretrizes Curriculares de Língua Estrangeira do Estado do Paraná (2009). As Diretrizes explicitam que a língua estrangeira proporciona um espaço de construção de conhecimento e interpretações da realidade através do discurso e do contexto, e não somente através da decodificação de um sistema linguístico. Tendo isto em mente, o livro didático analisado atenderia em boa parte a proposta na qual foi concebido.
\end{abstract}

Palavras-chave: interculturalidade; leitura em língua inglesa; Círculo de Bakhtin.

Abstract: The public textbook of Paraná State, used since 2009, tries to approach the process of teaching English through texts in a different way, following a path based on Bakhtin's theories of sociological perspective of language. This present work shows the relation between the sociological theory of language, supported by the Bakhtin's Circle and the texts in the book, seeking a relation between intercultural aspects and teaching English as foreign language. Starting by choosing a unit of the book, this present research analyzes the texts and activities in it, with the purpose of verifying if the author's intentions in teaching English based on the sociological perspective of language really take place. It intends to show the language theories of Bakhtin's Circle and its relation with the guidelines from Diretrizes Curriculares de Língua Estrangeira do Estado do Paraná. This document is based on the idea of using a foreign language to produce knowledge and interpretations of the reality through context and discourse, instead of doing it decoding a linguistic system. Following these ideas, the analyzed book covers almost all its proposals to teach a foreign language in an intercultural and sociological approach.

Keywords: interculturality; reading in English; Bakhtin Circle.

\section{CONSIDERAÇÕES INICIAIS}

O objetivo deste trabalho é analisar uma unidade do Livro Didático Público de Língua Estrangeira Moderna do Estado do Paraná (2006) a partir de suas condições de 
produção e dos pressupostos teóricos das Diretrizes Curriculares de Língua Estrangeira do Estado do Paraná.

De acordo com informações encontradas nas Diretrizes Curriculares de Língua Estrangeira Moderna do Estado do Paraná, este documento, que ajuda a nortear o trabalho dos professores, foi escrito com base em feedback dado pelos próprios profissionais da rede pública. Em encontros realizados a partir de meados da década de 1990 em vários núcleos regionais de educação, os professores puderam debater vários textos e discutir suas práticas. Foi a partir dessas discussões, das suas necessidades e limitações, de sua visão de Língua Estrangeira (LE), que as Diretrizes foram escritas.

A abordagem de ensino que prevalece na rede pública, segundo este documento, é a comunicativa, apesar das dificuldades que os professores relatam encontrar ao trabalharem com esta abordagem. Nesta abordagem, o principal objetivo das aulas é o de desenvolver a comunicação. "A língua é concebida como instrumento de comunicação ou de interação social, concentrada nos aspectos semânticos, e não mais no código linguístico.” (DIRETRIZES, 2009, p. 49). Entretanto, a partir dos anos 90, a abordagem comunicativa passou a ser alvo de críticas pelos pensadores da chamada pedagogia crítica. Estes críticos, muitos ligados ao pensamento de Paulo Freire, "passaram a questionar as intenções subjacentes ao ensino comunicativo de proporcionar o uso da língua estrangeira, por meio de estratégias conversacionais, para se inserir na outra cultura." (DIRETRIZES, 2009, p.48).

Os próprios organizadores das Diretrizes apontam várias limitações desta abordagem, uma delas com relação ao trabalho com a interculturalidade. Segundo os autores, o questionamento desta abordagem de ensino se deve ao fato de não dar ênfase à discussão dos aspectos que dizem respeito ao imperialismo e à hegemonia lingüística. (2009, p. 51)

Para isso, as Diretrizes (2009) baseiam-se na corrente sociológica e nas teorias do Círculo de Bakhtin, que concebem a língua como discurso. A partir disso, o documento traça seus principais objetivos, que são:

- o atendimento às necessidades da sociedade contemporânea brasileira e a garantia da equidade no tratamento da disciplina de Língua Estrangeira Moderna em relação às demais obrigatórias do currículo;

- o resgate da função social e educacional do ensino de Língua Estrangeira no currículo da Educação Básica; 
- o respeito à diversidade (cultural, identitária, linguística), pautado no ensino de línguas que não priorize a manutenção da hegemonia cultural. (p. 52)

Baseado na concepção bakhtiniana de linguagem, o objetivo da aula de Língua Estrangeira Moderna (LEM) deve ser o de levar o aluno a perceber "a diversidade linguística e cultura, de modo que se envolva discursivamente e perceba possibilidades de construção de significados em relação ao mundo em que vive" (DIRETRIZES, 2009, p. 53). Para se alcançar este objetivo, as diretrizes fundamentam-se na corrente sociológica de Bakhtin, na qual a língua é vista como discurso.

\section{CONCEPÇÃO DE LINGUAGEM PROPOSTA PELAS DIRETRIZES CURRICULARES DE LEM DO ESTADO DO PARANÁ E O LIVRO DIDÁTICO PÚBLICO DE INGLÊS}

Volochinov $^{1}$ (1986), um dos membros do Círculo de Bakhtin ${ }^{2}$, afirma que a linguagem é social. A linguagem necessita do sujeito para existir, já que sem o sujeito, o contexto e a história, o signo lingüístico não passa de uma palavra dicionarizada. A teoria sociológica de linguagem difere da teoria estruturalista, levando em conta não apenas a língua como sistema, mas também como a língua evolui e se comporta entre os seus falantes, no meio social na qual é utilizada.

Na realidade, não são palavras o que pronunciamos ou escutamos, mas verdades ou mentiras, coisas boas ou más, importantes ou triviais, agradáveis ou desagradáveis, etc. A palavra está sempre carregada de um conteúdo ou de um sentido ideológico ou vivencial. É assim que compreendemos as palavras e somente reagimos àquelas que despertam em nós ressonâncias ideológicas ou concernentes à vida. (VOLOCHINOV, 1986, p. 95, grifo do autor)

Para o Círculo de Bakhtin, a língua não se manifesta através de sinais, mas sim de signos que são condicionados social e historicamente. Para Volochinov, a palavra é o signo por excelência. Isso se deve a sua flexibilidade, uma vez que ela pode ser usada em qualquer contexto. A palavra é o signo que media todas as relações humanas, que

\footnotetext{
${ }^{1}$ A autoria de Marxismo e Filosofia da Linguagem é equivocadamente atribuída à Mikhail Bakhtin. O autor é V. N. Volochinov. Essa descoberta se deu, por meio de pesquisas sobre as autorias do Círculo de Bakhtin, a partir dos anos 80 (cf. FARACO, 2003).

${ }^{2}$ A expressão "Círculo de Bakhtin", como apresenta Faraco (2003), é usada para se referir ao conjunto da obra de um grupo de estudiosos que tinha Mikhail Bakthin como um de seus integrantes, juntamento com Volochinov, Medvedev e outros. Um dos assuntos de interesse em comum do grupo era a linguagem. O nome de Bakhtin é usado como referência à este grupo por ser o autor cuja obra é a maior entre os outros membros.
} 
está presente em todas as situações e é responsável por muitos entendimentos e também desentendimentos. Nas palavras do autor,

A palavra é o fenômeno ideológico por excelência. Na realidade toda palavra é absorvida por sua função de signo. A palavra não comporta nada que não esteja ligado a essa função, nada que não tenha sido gerado por ela. A palavra é o modo mais puro e sensível de relação social. (1986, p. 36, grifo do autor).

O Círculo de Bakhtin não vê a língua como código, mas sim como discurso. Segundo Jordão (2006),

[a] língua não é percebida como um código a ser decifrado, um emaranhado de pistas que devemos investigar. Ao invés de mediar nossas relações com o mundo, num mundo supostamente transparente e neutro, a língua constrói nosso mundo, e não apenas nomeia. Ela constrói discursos, produz efeitos de sentido indissociáveis dos contextos em que se constituem. Conceber língua como discurso é perceber a língua ideológica, perpassada por relações de poder que ela mesma constrói. (p.30).

Segundo Voloshinov (1986), a forma utilizada para se ensinar língua estrangeira em muitos métodos faz com que a palavra passe a ser apenas um sinal. Mesmo em língua estrangeira, o contexto social e cultural é fundamental para que aquela palavra seja absorvida como um signo, e não um sinal. Os falantes nativos não veem as palavras como itens de dicionários, mas sim como parte integrante de enunciações. É dessa forma que qualquer falante (nativo ou não) deveria ver e usar as palavras, apropriando-se delas para construir significados em seus contextos socioculturais.

Sob este ponto de vista, e com esta concepção bakhtiniana de língua, o ensino de LE não pode ser separado do contexto em que ela figura, uma vez que língua e situação social são indissociáveis. A língua é carregada de valores culturais e ideológicos, por isso, estudar uma língua é também saber a valoração e o peso que suas palavras têm. Um estudo fechado, tradicional, que separe língua e contexto ou que separe a língua de sua cultura é um equívoco no contexto da modernidade em que se vive. O estudo de uma LE deve desenvolver nos alunos uma consciência crítica com relação ao papel das línguas na sociedade, e, dessa forma, ir além de um ensino utilitarista e, muitas vezes, pouco eficaz. 
Um dos objetivos da disciplina de Língua Estrangeira Moderna é que os envolvidos no processo pedagógico façam uso da língua que estão aprendendo em situações significativas, relevantes, isto é, que não se limitem ao exercício de formas linguísticas descontextualizadas. Trata-se da inclusão social do aluno numa sociedade reconhecidamente diversa e complexa através do comprometimento mútuo. (...) Ao estudar uma língua estrangeira, o aluno/sujeito aprende também como atribuir significados para entender melhor a realidade. A partir do confronto com a cultura do outro, torna-se capaz de delinear um contorno para a própria identidade. Assim, atuará sobre os sentidos possíveis e reconstruirá sua identidade como agente social. (DIRETRIZES, 2009, p. 57)

Na prática, para se trabalhar sob a concepção proposta pelas Diretrizes, deve-se trabalhar com variados textos de forma significativa, isto é, de modo que seus leitores (alunos) sejam produtores de novos textos. A escolha dos gêneros textuais deve ser variada e condizente com o contexto social dos alunos. Sugere-se que seja feita uma leitura crítica dos textos, onde os alunos possam contribuir na construção dos sentidos, uma vez que não são sujeitos passivos. A leitura que visa o mero reconhecimento de informações não contribui para a formação do "discurso como prática social", que é o conteúdo estruturante das Diretrizes. Também não seria apropriada a segmentação entre oralidade, leitura e escrita, uma vez que esta separação não existe nas condições reais de interação social. (cf. DIRETRIZES, 2009, p.61)

Outra proposta que está intrinsecamente ligada com a perspectiva sociológica é a questão da cultura na sala de aula. Adotamos aqui não apenas a cultura ${ }^{3}$ como meio de transmissão da linguagem, mas também a relação entre as culturas através da linguagem. Percebemos que essa perspectiva sociológica proporciona ao aluno uma visão mais crítica sobre o que acontece no seu meio social, já que este sujeito terá ferramentas para comparar, contrastar, analisar, e (utilizando expressões do Círculo de Bakhtin) refletir ou refratar suas visões de mundo através da relação entre as culturas. Segundo Hexelschneider,

Interculturalidade é sempre o conhecimento e o reconhecimento do outro para aprofundar o autoconhecimento, sentir e repensar para entender melhor, ou até encontrar, a sua própria identidade. A interculturalidade não pode, de forma alguma, estabelecer uma comunicação de mão única do país da língua materna para o país da

\footnotetext{
${ }^{3}$ Partilhamos, neste contexto, com a visão de Eagleton sobre a definição de cultura. Para o autor, "cultura pode ser aproximadamente resumida como o complexo de valores, costumes, crenças e práticas que constituem o modo de vida de um grupo específico" (2005, p.54).
} 
cultura alheia/estranha - ela é muito mais um processo de mão dupla. (1987, apud Janzen, 1999, p. 8).

Para Almeida (2008), num mundo onde diferentes culturas coexistem, é preciso pensar em estabelecer relações entre as mesmas de tal forma que, ao entrar em contato com culturas diferentes, o ser humano possa ser levado a refletir de forma crítica sobre a cultura com a qual se depara bem como sua própria cultura, desenvolvendo assim uma competência intercultural, num exercício de questionamento, busca e construção de conhecimento que leve a uma interação mais significativa com o diferente.

O professor, é claro, deve ser o incentivador e mediador deste processo de reflexão sobre a interculturalidade e sobre o contexto do aluno. De acordo com Almeida (2008), para aplicar a abordagem intercultural na sala de aula não é preciso ser especialista em sociologia, antropologia ou estudos culturais. O que é preciso é saber observar criticamente as imagens, símbolos e produtos culturais, os padrões da rotina diária, valores e comportamentos que adotamos e compartilhamos em nossa cultura, e fazer o mesmo com relação a outras culturas. É essa capacidade de voltar um olhar crítico para nossas próprias vidas e a vida de quem é diferente de nós que precisamos exercitar com nossos alunos, ampliando assim nossa visão de mundo e desenvolvendo cada vez mais nosso respeito e entendimento do "outro".

Essa perspectiva intercultural é levada em conta nas Diretrizes Curriculares de LEM do Paraná, juntamente com as teorias do Círculo de Bakhtin. As Diretrizes ainda ressaltam que já o Currículo Básico de 1992 se fundamentava na perspectiva bakhtiniana de linguagem.

Dessa forma, este documento sugere que, melhor do que qualquer outra, a concepção sociológica seria a mais adequada a ser adotada pelos professores de LEM para se atingir o objetivo maior da educação: transformar os alunos em agentes sociais.

O Livro Didático Público de LEM do Estado do Paraná foi produzido então, segundo carta do Secretário da Educação ${ }^{4}$ no início do livro, com o intuito de suprir a falta de materiais didáticos de LE destinados ao Ensino Médio que sigam esta linha de desenvolvimento.

\footnotetext{
${ }^{4}$ Na publicação da primeira edição do Livro Didático Público de LEM, em 2006, o secretário da Educação do Paraná era Maurício Requião de Mello e Silva. A atual secretária é Yvelise Freitas de Souza Arco-Verde.
} 
Este livro é uma extensão de um projeto chamado "Folhas" da Secretaria de Educação do Estado do Paraná. Neste projeto, os professores da rede pública estadual podem inscrever propostas de trabalho ou unidades temáticas referentes à sua área de atuação. Estas propostas devem seguir a metodologia proposta pelas Diretrizes Curriculares de LEM do Estado do Paraná, passando por avaliação da Secretaria de Educação para publicação posterior no portal educacional do Estado.

O Livro Didático Público de LEM é, portanto, um agrupamento de alguns dos trabalhos inscritos no projeto "Folhas", como explicitado na carta destinada aos estudantes no início do livro: "O conjunto desses elementos que constituem o processo de escrita deste livro denomina cada um dos textos que o compõe de 'Folhas'." (Língua Estrangeira Moderna, 2006, p. 6).

E ainda:

Espera-se que, por meio desta metodologia, seja desenvolvida uma prática de pesquisa no cotidiano escolar e implementadas as Diretrizes Curriculares para Educação Básica da rede pública de ensino do Estado do Paraná. (Projeto Folhas. Disponível em: $<$ www.diaadia.pr.gov.br/projetofolhas $>$ Acesso em 12 de julho de 2009).

Por sua construção ser baseada nos trabalhos apresentados ao projeto "Folhas", espera-se que os pressupostos teóricos presentes nas Diretrizes sejam os norteadores da escolha metodológica das unidades do Livro Didático Público de LEM.

A partir desse pressuposto, foi feita a escolha de uma unidade do Livro Didático Público de Inglês (2006) a fim de verificar se os textos e atividades apresentadas refletem as propostas das Diretrizes de ensinar LE a partir de uma concepção sociológica intercultural. Os critérios usados para esta análise estão respaldados na concepção bakhtiniana de linguagem e nas orientações dadas pelas Diretrizes, uma vez que elas têm a função de orientar o trabalho do professor da rede pública e, consequentemente, também dos autores do Livro Didático Público.

\section{ANÁLISE DA UNIDADE "SHAKESPEARE AND 'TEN THINGS I HATE ABOUT YOU" " DO LIVRO DIDÁTICO PÚBLICO DE LEM DO ESTADO DO PARANÁ}

O livro didático público de LEM do Estado do Paraná é destinado para uso no Ensino Médio da rede estadual. O livro apresenta nove unidades e tem o intuito de trabalhar com a LE por meio da leitura. 
A unidade escolhida para análise foi a primeira, intitulada "Shakespeare and 'Ten Things I Hate About You'”. Nesta unidade, a autora busca fazer uma comparação entre uma das obras de Shakespeare e a comédia romântica "Ten Things I Hate About You." O objetivo é mostrar como a obra de Shakespeare tem ganhado releituras modernas ao estabelecer a relação com um filme muito popular entre o público adolescente.

Para se fazer essa análise, foram levados em conta vários aspectos da concepção bakhtiniana de linguagem e os apontamentos presentes nas Diretrizes. Dessa forma, o primeiro item a ser analisado é a escolha dos textos. De acordo com as propostas para uma abordagem intercultural ${ }^{5}$, o ensino de língua estrangeira é mais bem desenvolvido quanto têm como suporte o texto autêntico ${ }^{6}$. Este tipo de texto pode ser usado para a prevenção de imagens estereotipadas e preconceitos com relação à cultura da língua em estudo, além de ser um grande aliado no estudo dos gêneros e da estrutura composicional do texto. Apesar disso, mesmo o texto que carregado de estereótipos pode trazer a tona discussões interessantes sobre a cultura alvo, levando o aluno a refletir sobre o processo de construção e identificação destes estereótipos.

Outro item verificado foram as questões referentes ao texto. De acordo com o documento que embasa este trabalho, o texto não deve ser usado com o objetivo de se ensinar estruturas gramaticais, sintáticas ou lexicais. Estes pontos podem ser abordados, mas o objetivo é que eles sirvam como ferramenta para construir sentidos do texto, auxiliando o aluno na compreensão do texto, do gênero, do contexto em que foi escrito, e na sua interpretação.

Um terceiro ponto analisado refere-se à presença ou não de um interlocutor. Segundo a concepção dialógica de linguagem, todos os enunciados são dirigidos a um interlocutor e a construção de sentidos é feita na alteridade ${ }^{7}$. A ausência desse interlocutor, a construção de uma unidade temática fechada e monológica, acabam caracterizando-a como um ilusório discurso de verdade ${ }^{8}$, uma vez que nenhum discurso é completo e fechado em si mesmo.

Outro aspecto ainda a ser analisado é a questão do trabalho com os gêneros textuais. As Diretrizes enfatizam muito que o trabalho com os mais variados gêneros é

\footnotetext{
${ }^{5}$ Cf. MEIRELES 2002 e SCHLATTER 2000.

${ }^{6}$ Nos referimos aqui a textos retirados de contextos reais de comunicação como, por exemplo, artigos de jornal, textos publicitários, sites de internet, etc.

${ }^{7} \mathrm{Na}$ relação com o outro.

${ }^{8}$ Cf. GRIGOLETTO, 1999.
} 
primordial, uma vez que é através da escolha do gênero mais apropriado que o professor consegue aproximar o contexto do aluno à aula de língua estrangeira, tornado-a algo significativo em sua vida.

Seguindo a proposta do projeto "Folhas" e a concepção sociológica de linguagem adotada pelas Diretrizes e pelos colaboradores do livro, a unidade 1 do Livro Didático Público de Inglês traz como idéia principal a intertextualidade. A proposta principal seria comparar a vida de adolescentes nos EUA e no Brasil, usando como recurso o filme "Ten Things I Hate About You", baseado na obra de Shakespeare. Outro foco é o trabalho com gêneros textuais (film reviews, por exemplo). Além disso, os alunos teriam a oportunidade de conhecer a vida e obra de William Shakespeare, escritor britânico de renome mundial, e aproximar esse assunto da sua realidade.

A introdução da unidade apresenta uma conversa com o aluno, mantendo-o como interlocutor por toda a unidade. O capítulo começa com uma série de perguntas dirigidas diretamente ao aluno leitor do livro. A primeira quer saber se ele, o aluno, quer aprender o inglês "de verdade", ou seja, aquele com expressões, gírias, formas curtas. Por esse ponto, já se pode observar que a concepção de língua da autora deste capítulo não é da língua como um sistema fechado e as variações não são vistas como deformidades da língua. Em seguida, é mencionada a rotina das escolas americanas e uma comparação será feita com as escolas brasileiras. As últimas perguntas dizem respeito ao autor e ao filme que dão nome ao capítulo: o que eles têm a ver com esse assunto.

Ao longo da unidade, percebe-se a tentativa de estabelecer uma conexão entre o assunto a ser estudado e a vida cotidiana dos alunos. Utilizar Shakespeare, por exemplo, como mote para a introdução da unidade não é algo fácil de trabalhar ou de despertar interesse nos alunos. Por isso, a idéia de relacionar as peças do autor com um filme comercial de larga escala (o qual os alunos provavelmente já assistiram e gostaram, pois representa a vida adolescente e as paixões juvenis) representa um recurso efetivo do ponto de vista metodológico.

O livro traz uma breve biografia de Shakespeare retirada de um site da internet. Também traz um texto de internet sobre o filme "Ten things I hate about you" que foi adaptado. Com essas informações, os alunos têm a oportunidade de perceber que as duas realidades apresentadas não estão distantes, já que o filme foi baseado numa das peças de Shakesperare. Aqui os alunos podem fazer comparações sobre as versões, questionar a possibilidade de adaptação de obras literárias e trazer essas obras para 
refletir sobre suas próprias experiências sociais. Há perguntas para serem discutidas por alunos e professor, a fim de identificar o conhecimento prévio dos alunos acerca do escritor e de sua obra.

Em seguida, o livro sugere que o filme seja assistido. Também propõe uma série de questões para reflexão sobre o comportamento dos jovens americanos, com base no filme, e brasileiros e também de questões culturais como as semelhanças e diferenças entre as escolas, o preconceito contra mulheres, o amor na adolescência, entre outros. Estas sugestões estabelecem uma grande aproximação com a realidade dos alunos, pois por meio da comparação entre o sistema escolar americano e brasileiro, os sujeitos se percebem como agentes neste mundo, e podem modificar essa existência ou apenas refletir sobre ela, trazendo um grau mais elevado de criticidade para a sala de aula.

O livro traz também três comentários sobre o filme, que foram postados na internet, e questões elaboradas para a reflexão dos textos, que buscam ver se o aluno compreendeu o conteúdo dos textos. Não há questões gramaticais. O livro propõe como atividade final duas opções de escrita cujos gêneros que já haviam sido apresentados anteriormente. Em uma das opções, o aluno pode escrever seu próprio comentário sobre o filme. Na outra, o aluno pode escrever um poema ou uma lista com o mesmo título do filme, como o que foi feito por uma das personagens do filme. Quando apresenta os comentários sobre o filme, as questões que se seguem conduzem o aluno a uma reflexão sobre esse gênero. Os alunos são levados a identificar qual comentário é positivo e qual é negativo, da mesma forma que são conduzidos a identificar nos comentários as relações entre o filme e as obras de Shakespeare.

Além dessas atividades, o livro ainda traz uma lista de expressões e gírias que foram retiradas do filme. Um dos objetivos da unidade é, de fato, o de mostrar que a língua inglesa vai além das frases prontas e gramaticalmente corretas que os alunos comumente aprendem.

Apesar destes aspectos positivos, a unidade ainda apresenta algumas limitações que podem gerar dificuldade para o desenvolvimento da aula. Uma delas pode ser observada em uma das questões elaboradas para a discussão do filme: "What are the references showed in the film '10 Things I Hate About You', about Shakespeare writings? (Try to watch some parts of the film again to confirm these references)." (LÍNGUA ESTRANGEIRA MODERNA, 2006, p. 164). Ver e rever o filme em sala de aula com certeza não é o maior problema nas escolas estaduais paranaenses, visto que todas as salas de aula são equipadas com uma TV-pendrive, a qual o professor tem a sua 
disposição sempre que necessitar, ou seja, o problema não é com relação a equipamentos, ou falta destes. O problema maior da questão está na relação que os alunos terão que estabelecer entre as obras de Shakespeare, e o filme assistido, ou seja, de ordem metodológica. Observar relações e evidências da forma que o livro propõe pode não ser tarefa fácil nem mesmo para aqueles que conhecem um pouco da obra shakespeariana. E os adolescentes? Possuem leituras suficientes para fazer tais inferências? Todavia, mesmo com essas limitações, essas relações podem ser estabelecidas de forma mais próxima ao aluno usando artifícios como assistir a cena do filme em que a protagonista declama uma versão de um poema de Shakespeare e, assim, encorajar os alunos a recitarem textos de sua escolha, de acordo com seus gostos pessoais. Essa é apenas uma das possibilidades de trabalho dentro deste contexto.

Vale ressaltar, entretanto, que, seguindo as orientações das Diretrizes e da teoria sociológica de linguagem, esta unidade escolhida para análise demonstra uma grande preocupação com o contexto social do aluno, levando-o a refletir sobre o que acontece dentro da sua realidade, como esse processo acontece fora dela e como o aluno, como sujeito, pode desenvolver uma capacidade intercultural e crítica sobre os tópicos abordados. Aqui o aluno tem a chance de se expressar ativamente, tendo contato com a língua estrangeira não com base em exercícios de gramática, mas sim com textos e discussões sobre produções em Língua Inglesa, compartilhando conhecimento com outros sujeitos e questionando o seu universo sociocultural por meio da comparação com outros contextos.

\section{CONSIDERAÇÕES FINAIS}

Que uma abordagem sociológica intercultural é a mais apropriada para o contexto de ensino de LE que se configura atualmente, quase todos envolvidos no debate educacional já tangenciaram este ponto. Entretanto, o que se vê é uma falta de exemplos práticos, concretos dessa abordagem sendo desenvolvida. Dessa forma, o Livro Didático Público de LEM é uma tentativa de materializar o que tantos pesquisadores têm ressaltado a respeito do ensino de línguas.

\section{REFERÊNCIAS:}


ALMEIDA, M. Seminários sobre interculturalidade - Em busca do resgate da cultura no ensino de línguas estrangeiras. Disponível em: $<$ http://br.geocities.com/ceecle05/resgate_cultura_les.doc $>$. Acesso em 03 de julho de 2009.

BAKHTIN, M.(V. N. Volochínov). Marxismo e Filosofia da Linguagem. São Paulo: Hucitec, 1986.

EAGLETON, T. A Idéia de Cultura. São Paulo: Editora Unesp, 2005.

FARACO, C. A. Linguagem e Diálogo: as idéias lingüísticas do círculo de Bakhtin. Curitiba: Editora Criar Edições, 2003.

GRIGOLETTO, M. Leitura e Funcionamento Discursivo do Livro didático. In: CORACINI, M.J.R.F. (Org.). Interpretação, autoria e legitimação do livro didático: língua materna e língua estrangeira. 1 ed. Campinas, SP: Pontes, 1999.

JANZEN, H. Mediação cultural, abordagem comunicativa e ensino de língua estrangeira: o conceito lingüístico de Bakhtin e os pressupostos da interculturalidade. São Paulo, 1998. 94 f. Dissertação (Mestrado em Letras). Universidade de São Paulo.

JORDÃO, C. O ensino de línguas estrangeiras - de código a discurso. In: KARWOSKI, A. M.; BONI, V. (Orgs.). Tendências contemporâneas no ensino de inglês. União da Vitória, PR: Kaygangue, 2006, p. 26-32.

LÍNGUA ESTRANGEIRA MODERNA - Espanhol e Inglês / vários autores. Curitiba: SEED-PR, 2006.

MEIRELES, S.M. Língua Estrangeira e autonomia: um exemplo a partir do ensino de alemão no contexto brasileiro. In: Educar, Curitiba, n.20, p.149-164. 2002. Editora UFPR.

PROJETO FOLHAS. Disponível em: <www.diaadia.pr.gov.br/projetofolhas>. Acesso em 12 de julho de 2009.

SCHLATTER, Margarete. Inimiga ou aliada? O papel da cultura no ensino da língua estrangeira. In: INDURSKY, F. \& CAMPOS, M.C. (org.) Discurso, memória e identidade. Coleção Ensaios. Porto Alegre: Sagra, 2000. p.517-527.

SEED-PR. Diretrizes curriculares de língua estrangeira moderna para a Educação Básica, Curitiba, PR, 2009. Disponível em <www.diaadiaeducacao.pr.gov.br>. Acesso em 30 de junho de 2009. 